\title{
Historiadores e memória da historiografia no Rio Grande do Sul: a ediçāo póstuma de Terra Gaúcha (1955), de Simōes Lopes Neto
}

\author{
Historians and memory of historiography in Rio Grande do Sul: the \\ posthumous edition of Terra Gaúcha, by Simōes Lopes Neto
}

Jocelito Zalla

\section{RESUMO}

O objetivo deste artigo é examinar o aparato paratextual póstumo de Terra Gaúcha (1955), ensaio histórico inédito do escritor regionalista João Simões Lopes Neto (1865-1916). Quais eram as condições (e os limites) da apropriação da obra e do autor no período da edição? Para tanto, busco aliar uma história editorial do manuscrito a uma tipologia das notas de rodapé elaboradas pelos historiadores-editores. A edição de Terra Gaúcha visava legitimar as posições adotadas pelo grupo de historiadores-folcloristas marginal no âmbito do Instituto Histórico e Geográfico do Rio Grande do Sul (IHGRS), criando um precursor nobre e uma narrativa de memória para seu projeto de escrita de história. Essa operação passou pela atualização científica do texto, através da inclusão de notas de rodapé bibliográficas e documentais, e pela concessão ideológica a teses então dominantes a respeito da formação do Rio Grande do Sul. Essa autorização parcial, no entanto, acabou por reforçar o veto à identidade profissional de historiador para Simões Lopes Neto.

\section{PALAVRAS-CHAVE}

Historiografia sul-rio-grandense; Nota de rodapé; Historiadores.

\section{ABSTRACT}

The purpose of this article is to examine the posthumous paratextual apparatus of Terra Gaúcha (1955), unpublished historical essay of regionalist writer João Simões Lopes Neto (1865-1916). What were the conditions (and limits) of the uses of the work and its author in the period of the edition? Therefore, we seek to combine an editorial history of the manuscript to a typology of the footnotes prepared by historians-editors. The edition of Terra Gaúcha aimed at legitimizing the positions taken by the group of marginal historiansfolklorists in the Historical and Geographical Institute of Rio Grande do Sul - Brasil (IHGRS), creating a noble precursor and a memory narrative for its own writing history project. This operation allowed the scientific updating of the text, by including bibliographic and documentary footnotes. It also needed an ideological concession to the dominante historic theses about the social formation of Rio Grande do Sul. This partial authorization, however, turned out to strengthen the veto for a professional identity of historian to Simões Lopes Neto.

\section{KEYWORDS}

Sul-rio-grandense historiography; Footnotes; Historians. 
Hoje reconhecido como ficcionista, João Simões Lopes Neto (1865-1916) foi um daqueles intelectuais da Primeira República, denominados de "polígrafos" por Sergio Miceli: um pequeno produtor independente que vivia dos rendimentos de várias modalidades de produção escrita (MICELI 2001, p. 54). Foi periodista, dramaturgo, folclorista e pretendeu-se historiador. Entre 1906 e 1910, redigiu um ensaio didático sobre a história do Rio Grande do Sul, Terra Gaúcha, que foi recusado pelas editoras do nicho educativo no estado. A redescoberta desse manuscrito inédito, referente ao primeiro volume do livro, aconteceu nos anos 1940, no âmbito dos esforços de resgate crítico de sua obra de ficção publicada, Contos Gauchescos (1912) e Lendas do Sul (1913), capitaneados pelo poeta Augusto Meyer e pelo jornalista Carlos Reverbel, e que envolveram outros escritores da primeira geração modernista sul-riograndense e sua rede nacional. Em 1955, Terra Gaúcha foi publicado pela Sulina, após ter sido rejeitado pela Globo, ${ }^{1}$ que então reeditava a literatura simoniana. $O$ texto foi prefaciado e anotado pelos historiadores Manoelito de Ornellas e Walter Spalding, buscando emendar equívocos factuais, lacunas documentais e algumas interpretações.

O objetivo deste artigo é analisar o aparato paratextual póstumo do livro, principalmente as notas de rodapé, que oferecem um sistema de mediação da leitura do ensaio que passa pelos debates de memória histórica dos anos 1950. De que maneira Terra Gaúcha foi usado nesses confrontos historiográficos? Como veremos, um grupo marginal do Instituto Histórico e Geográfico do Rio Grande do Sul (IHGRS), do qual faziam parte Ornellas e Spalding, encontrou no ensaio simoniano relações com sua própria produção, o que levou à construção do personagem como um precursor da historiografia gaúcha. Ao lançar a obra tantas vezes rejeitada, os historiadores-editores buscaram elaborar uma narrativa de memória para seu próprio projeto de escrita da história, além de se notabilizarem no campo intelectual como agentes da reparação. Quais os limites dessa invenção?
1. A Livraria do Globo, de Porto Alegre, se tornou casa editora independente na década de 1930. Especializada em tradução, principalmente de literatura de língua inglesa (ramo ainda pouco explorado pelas concorrentes na época), estendeu sua rede de distribuição por todo o país. Nos anos 1940, era a segunda maior editora brasileira em número de títulos publicados, atrás apenas da Companhia Editora Nacional, de São Paulo. 


\section{Literatura e história: fluxos intelectuais e bases editoriais}

A história do ensaio histórico de Simões Lopes Neto parece sintomática das relações entre literatos e historiadores no Rio Grande do Sul. A recusa do livro pelas autoridades públicas no setor de educação levou ao empenho também frustrado de edição. Entre as peripécias por que passou o manuscrito, está a perda de parte dele pelo contista e romancista Alcides Maya, escolhido a dedo por Simões para ser o prefaciador de sua obra de estreia nas artes de Clio. A "redescoberta" da primeira parte do livro não foi menos romanesca. Tudo começou com uma visita de Manoelito de Ornellas a Pelotas, em 1942. Naquele momento, o poeta da primeira geração modernista/regionalista do Rio Grande do Sul já era dono de uma vasta carteira de títulos, tendo lançado ensaios históricos, folclóricos e de crítica literária², 0 que Ihe rendeu convite para palestrar na Biblioteca Pelotense, tendo como um dos temas a literatura simoniana. Ornellas foi apresentado à viúva de Simões Lopes, Francisca Meirelles Simões Lopes, conhecida como Dona Velha. Nos anos seguintes, ela recorreu ao escritor para tentar recuperar a segunda parte de Terra Gaúcha junto a Alcides Maya, no que não foi bem-sucedida. ${ }^{3}$ Mas a confiança depositada no escritor teria como contrapartida seu compromisso com a edição do ensaio histórico, que levaria mais de uma década para se concretizar.

Ornellas foi talvez o primeiro intelectual atuante na capital gaúcha a consultar o famoso baú que continha os resíduos do acervo simoniano original. ${ }^{4}$ Possuindo trânsito na Editora Globo, encaminhou o ensaio histórico para avaliação da casa, no mesmo momento em que Aurélio Buarque de Holanda preparava a edição crítica dupla de Contos Gauchescos e Lendas do Sul. No entanto, a empolgação dos editores entrou em choque com a interdição de dois influentes intelectuais da empresa. Coube ao poeta Augusto Meyer, provavelmente na sombra do crítico e historiador Moysés Vellinho - diretor da revista de perfil erudito da Globo, Província de São Pedro -, dar o parecer definitivo: Terra Gaúcha era historiografia
2. Além dos livros de poesia Rodeio de Estrelas (1928) e Arco-Íris (1930), Ornellas havia publicado até a data Dois discursos (1930), Tupanciretã (1934) - ensaio sobre a história da região missioneira Vozes de Ariel (1938) - crítica literária -, Tradições e Símbolos (1940) - folclore e cultura regional.

3. Em cartas trocadas com Manoelito de Ornellas em 1942, Dona Velha conta que confiou o segundo volume de Terra Gaúcha a Alcides Maya numa de suas passagens por Pelotas. Junto a uma missiva de 1943, ela envia o primeiro volume da obra a Ornellas. Em 1944, sabendo da viagem do escritor ao Rio de Janeiro, ela solicita sua intervenção junto a Alcides Maya, na tentativa de recuperar o trecho perdido (SIMÕES LOPES 1944, p. 62).

4. É de 1943 a carta em que a viúva relata a Ornellas ter recebido do Rio de Janeiro um baú com manuscritos de Simões Lopes Neto. 
desatualizada, equivocada em muitos pontos e, inclusive, carente da qualidade textual encontrada nos Contos e nas Lendas.

É verdade que a própria Dona Velha teve responsabilidade sobre a demora da publicação e o recuo da Globo, pois não contava com a recepção negativa em seu núcleo duro de intelectuais, reservando a empresa como uma opção derradeira para o livro. Queria, antes, esgotar seus recentes contatos no Rio de Janeiro e em São Paulo. ${ }^{5}$ Entusiasmada com o novo sucesso da obra de ficção, ela acreditava que o ensaio histórico despertaria interesse de editoras do centro do país. Como a expectativa não se materializou, a viúva ofereceu o texto ao Instituto Nacional do Livro, então dirigido por Meyer. Em carta de abril de 1954, o poeta gaúcho não apenas rejeitou a proposta como desaconselhou a publicação da obra. A justificativa se ancorava na atribuída superioridade do literato sobre o historiador: "Bastou a leitura de algumas páginas para deixar bem claro que não se trata, no caso, do genuíno Simões Lopes, mas sim de um simples esboço histórico, bastante incompleto, e já de há muito superado pelas últimas pesquisas" (MEYER 1954, p. 128). Dessa forma, o lançamento da obra seria um "desserviço a sua memória" (MEYER 1954, p. 128). Na retomada do contato com a Globo, Dona Velha foi mais uma vez surpreendida com uma recusa, ainda que, dessa vez, disfarçada pela alegação de dificuldades financeiras que impediam a edição.

Nas décadas de 1940 e 1950, embates entre os intelectuais locais pelos critérios de redefinição do regionalismo gaúcho (CORADINI 2003, p. 134) levaram a novos agrupamentos e polarizações que dividiam a primeira geração modernista do Rio Grande do Sul. Havia, por certo, condições estruturais bastante distintas daquelas dos anos 1920, quando seus principais nomes surgiram na esfera pública. Primeiro, a dinâmica institucional tornava-se mais complexa, com o surgimento das universidades, a reorganização de academias de letrados e a consolidação de lugares de memória e de pesquisa alternativos ao IHGRS, como o Museu Júlio de 
Castilhos (MJC). Segundo, houve grande desenvolvimento do mercado brasileiro de livros, que integrou autores e editoras locais ao circuito nacional. Nesse âmbito, o antigo grupo modernista da Globo mantinha na empresa seu núcleo duro, com a colaboração de Augusto Meyer e Moysés Vellinho. Na segunda maior editora do país no período, esses intelectuais lançaram projetos arrojados como a Coleção Província, de livros de temática local, e a já citada Revista Província de São Pedro, que buscavam delimitar o cânone literário e historiográfico sul-rio-grandense. Outros intelectuais, como Manoelito de Ornellas e Walter Spalding, obtinham abrigo em editoras concorrentes. É nesse contexto que o tratamento desigual dado à produção ficcional e historiográfica de Simões Lopes Neto deve ser compreendido.

Em 1948, Ornellas já havia anunciado o ensaio simoniano inédito em sua coluna no Correio do Povo. Na ocasião, levantou com pouca precisão uma série de títulos do autor, entre publicados e inéditos, incluindo datas equivocadas das edições Echenique dos Contos e das Lendas. O objetivo do texto, segundo Ornellas, seria atrair "o interesse dos editores, para uma obra completa, revista e selecionada" (ORNELLAS 1948a, p. 4). A coluna, portanto, cumpria uma função de divulgação e, dada a atenção detalhada a Terra Gaúcha, pode ser considerada seu primeiro epitexto público póstumo, espécie de prolongamento alógrafo (não autoral) do texto para fora do espaço material do livro, compondo ou determinando parte de seu significado. A indicação do interesse da Globo, naquele momento, também podia ser estratégica, comprometendo a editora com o ensaio histórico de Simões Lopes Neto.

A imprecisão factual da primeira notícia de Ornellas demonstra o estado precário da circulação simoniana até a edição crítica de Holanda, lançada pela Globo em 1949. Mas sua publicação, em fase inicial de consagração, também aponta que o projeto coletivo de resgate do autor mobilizava facções diferentes da intelectualidade local. Apesar de seu 
trânsito relativamente tranquilo na maior casa editora gaúcha, com publicação de alguns de seus livros, parece significativo que Manoelito de Ornellas tenha editado seus trabalhos mais polêmicos em empresas concorrentes, inclusive de fora do estado. Gaúchos e beduínos (1948), por exemplo, que causou grande comoção na cena pública local por declarar unidade histórica e identidade comum entre o Rio Grande do Sul, o Uruguai e o norte da Argentina, foi publicado pela José Olympio. ${ }^{6}$ As posições de Ornellas, assim, feriam os brios nacionalistas do núcleo duro da Globo, ${ }^{7}$ entrando em choque constante com Moysés Vellinho. Ao se fazer historiador, o editor da Província de São Pedro passou a aglutinar a corrente memorialista lusitanista do Instituto Histórico e Geográfico do Rio Grande do Sul (IGHRS), após seu ingresso como sócio efetivo na instituição, em 1949. Ornellas era seu antagonista, considerado o herdeiro da tradição historiográfica platinista que remontava a Alcides Lima e Alfredo Varella.

O amigo de Dona Velha, então, acionou Walter Spalding, seu colega no IHGRS, para se somar à edição de Terra Gaúcha. Ambos, nos anos 1950, encontravam acolhida editorial na segunda maior casa editorial de Porto Alegre, a Sulina. ${ }^{8} \mathrm{O}$ ensaio histórico de Simões foi lançado na Coleção Meridional, que já publicara Gênese do Brasil-Sul (1953), de Spalding, e que provavelmente configurava um contraponto à Coleção Província. Ornellas redigiu uma apresentação. O colega convidado providenciou notas de rodapé para a atualização do texto. Na história das correntes historiográficas sul-riograndenses, Spalding é comumente identificado ao platinismo de Ornellas. Esse dado, em si, já é bastante significativo, uma vez que levanta a hipótese de que o conteúdo do livro condiz com as posições defendidas pelos historiadores dissidentes do Instituto, "adversários permanentes e, eventualmente, aliados táticos" (NEDEL; RODRIGUES 2005, p. 172) de autores como Vellinho. Seus investimentos na pesquisa da cultura popular encontram balizas na obra simoniana. Mas a apropriação do escritor pelotense por esse grupo exigiria um grande trabalho de mediação.
6. Gaúchos e beduínos: a origem étnica e a formação social do Rio Grande do Sul foi publicado na Coleção Documentos Brasileiros, dirigida por Octavio Tarquinio de Souza. Pelas edições a que tive acesso, parece que a José Olympio continuou reimprimindo o título até 1976. A partir de 1999, o livro passou a ser editado pela Martins Livreiros, casa gaúcha especializada em títulos regionalistas, fundada como livraria nos anos 1960.

7. A exceção de Erico Verissimo, consultor da Globo e seu principal escritor, que apostou em respostas ficcionais semelhantes às dos historiadores-folcloristas para a formação do Rio Grande no romance $O$ continente (1949), primeiro volume da trilogia O Tempo e o Vento. Em comparação a Ornellas, acredito que seu caso demonstra mesmo que a possibilidade de representar sujeitos e eventos incômodos para a patrulha nacionalista e elitista dos intelectuais estabelecidos, ainda que em contraponto com suas visões tradicionais da história gaúcha, era então praticamente restrita à literatura de imaginação. No discurso histórico-folclórico, a opção pelo popular exigia outras bases editoriais e institucionais, como veremos a seguir.

8. A Editora Sulina não constituiu arquivo de acesso público. Nos anos 1990, ela foi vendida para o Grupo Meridional, que mantém o selo Sulina até hoje. Não consegui mapear dados precisos de sua trajetória para o período abordado. Mas a pesquisa das obras publicadas pelos intelectuais gaúchos deixa claro que ela era, no estado, a principal via de escape para os títulos históricos e folclóricos considerados problemáticos pela patrulha nacionalista dominante no IHGRS e na Editora Globo. 


\section{Uma memória da história gaúcha: Simōes Lopes Neto como documento}

O aparato gráfico da edição Sulina é a porta de entrada mais óbvia para o projeto de Ornellas e Spalding. A capa ostenta a assinatura original de Simões Lopes Neto, junto ao título do livro e ao selo da Coleção Meridional (Figura 1). A primeira folha de rosto traz uma gravura que reproduz o semblante conhecido de escritor (Figura 2), divulgado em profusão nas recentes reportagens biográficas de Carlos Reverbel para os periódicos da Globo, no intuito de promover sua obra de ficção. A segunda folha de rosto apresenta, mais uma vez, o nome do autor, junto ao título do ensaio e aos nomes dos prefaciadores. Segundo Gerard Genette, "quanto mais o autor é conhecido, mais seu nome é exibido" (GENETTE 2009, 40). Fica claro, portanto, que já era possível, em 1955, recolher em outras searas os dividendos simbólicos do trabalho de consagração póstuma de Simões Lopes realizado pelos literatos modernistas.

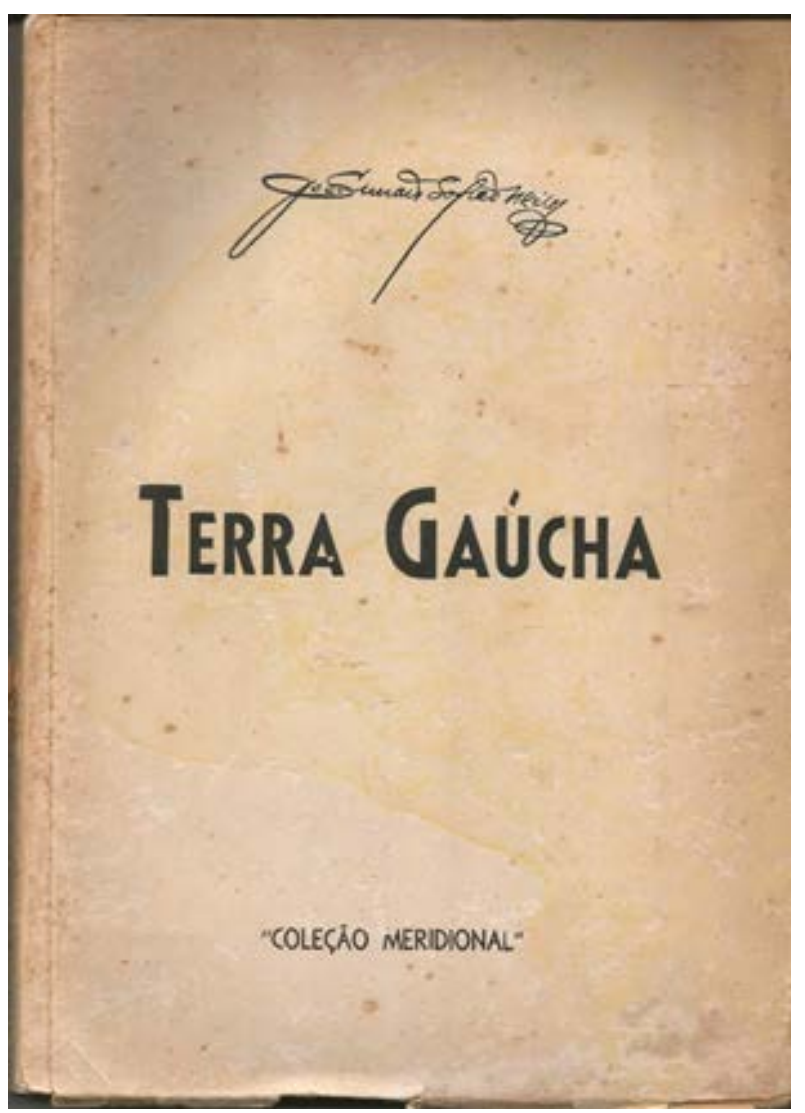

Figura 1: Capa da edição Sulina de Terra Gaúcha (1955) 


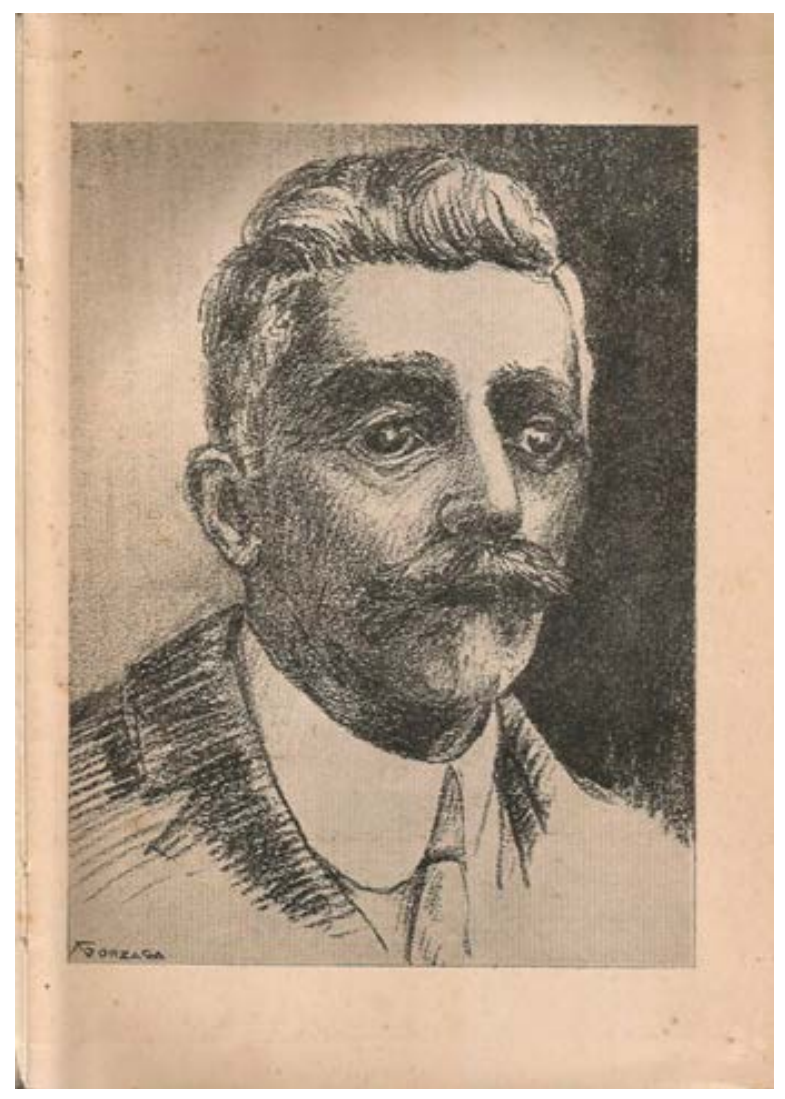

Figura 2: Folha de rosto de Terra Gaúcha

No plano dos peritextos escritos, tanto Ornellas, o mentor da edição, quanto Spalding, o encarregado da notação, dialogam com os argumentos contrários à publicação do ensaio. Como que respondendo diretamente à carta de Meyer a Dona Velha, o primeiro diz, em seu prefácio, que "'Terra Gaúcha' não desmerece em nada da obra do ficcionista insigne" (ORNELLAS 1955, p. 8). Spalding, na Introdução, afirma a unidade estilística: "Quem conhece e leu com atenção os 'Contos Gauchescos' e demais obras publicadas de Simões Lopes Neto, encontra-lo-á também nesta integralmente" (SPALDING 1955, p. 10-11). A réplica legitima a publicação do ensaio através da mobilização do principal trunfo simoniano na crítica modernista: o trabalho de linguagem. Vale ressaltar ainda que, segundo a história da historiografia tradicional rio-grandense, a qualidade estilística podia ser valorizada mesmo em textos de ambição científica, como os produzidos no âmbito do IHGRS depois de 1920 (SILVEIRA 2008, p. 42). Não é difícil sustentar que esse padrão tenha persistido na produção do Instituto até os anos 1950 ou, pelo menos, que a existência de antecedentes estilísticos 
recentes na produção de historiadores reconhecidos poderia dar suporte ao lançamento de Simões Lopes Neto na esfera historiográfica.

Tratava-se, portanto, da reabilitação da faceta historiadora na imagem pública do autor. Para Spalding, a primeira parte de Terra Gaúcha e a nota preliminar sobreviventes "demonstram a capacidade imensa de J. Simões Lopes Neto e Ihe dão direito de figurar entre nossos historiadores do período pré-histórico, isto é, do Rio Grande terra de ninguém [...]" (SPALDING 1955, p. 10). Período de formação, segundo o prefaciador, ainda não estudado no tempo de Simões, o que atestava seu pioneirismo e permitia desculpar os equívocos cometidos:

Não se conhecia, então, a vasta documentação trazida a lume anos mais tarde, propriamente a partir de 1930, por historiadores da força de um Rego Monteiro, de um Borges Fortes, de um Osvaldo Cabral, entre nós, no Brasil, e por Azarola Gil entre os platinos. Por isso, pequena também era a bibliografia que, aliás, Simões Lopes Neto nem refere sequer. E quanto à documentação original, esta jazia ainda coberta de pó nos diversos arquivos nacionais e estrangeiros (SPALDING 1955, p. 10).

A localização temporal de Terra Gaúcha no "período préhistórico" permitia, assim, conferir lugar distinto a Simões Lopes Neto numa também pré-história da história gaúcha, entre os autores que antecederam a profissionalização da pesquisa, avalizando sua identificação com a imagem social de historiador, mesmo que lhe faltassem os atributos exigidos para isso nos anos 1950. Segundo, trazia a necessidade editorial de revelar ao leitor os avanços recentes da historiografia, dos quais o autor não pôde participar, com um aparato de notas detalhado, baseado nos critérios de legitimidade construídos nas décadas anteriores por historiadores estabelecidos. A referência à documentação é bastante relevante, uma vez que dialoga diretamente com a história da historiografia gaúcha, para nela inscrever a dupla temporalidade da obra e de seus novos paratextos editoriais. Para Silveira, os preceitos fundadores dos estudos do IGHRS, na década de 1920, 
passavam pela valorização do documento escrito e oficial. Seriam critérios de apreciação o concurso às fontes em abundância, o que reforçava o estatuto de prova do documento, e o seu ineditismo (SILVEIRA 2008, p. 29). ${ }^{9}$ Nedel também aponta que o processo de institucionalização da pesquisa histórica, naquele momento, "trouxe consigo o refinamento da crítica externa documental e do controle da procedência das fontes escritas" (NEDEL 1999, p. 136).

Entende-se, assim, porque a elaboração das notas de rodapé de Terra Gaúcha apoiava-se nos seguintes critérios: a) atualização bibliográfica; b) vasta documentação; c) documentos inéditos e/ou pouco conhecidos; e d) fontes de procedência confiável. Tanto as notas probatórias quanto as de caráter contestatório passavam pelo crivo documental.

Antes de partirmos para a análise do trabalho de Spalding, vale refletir sobre a condição da nota de rodapé no contexto local da pesquisa histórica. Como apontado por Anthony Grafton, a exigência de acompanhamento do relato histórico por notas sistemáticas sobre as fontes do autor é uma regra da "erudição histórica profissional" (GRAFTON 1998, p. 38). Segundo Silveira, a prática da anotação é característica da produção inicial do IHGRS. A unidade textual da historiografia do período é dada pela profusão de notas de rodapé, além da assinatura, do estilo pessoal e da ambição de verdade (SILVEIRA 2008, p. 38). Documentos e referências bibliográficas eram, assim, mobilizados para a construção de um discurso coletivo que legitimava o trabalho do historiador, corroborando "seus temas, suas posições e suas conclusões" (SILVEIRA 2008, p. 39). A prática da anotação alógrafa também era comum, tanto em nível local quanto nacional, exercendo funções semelhantes. Às vésperas do centenário da Guerra dos Farrapos, por exemplo, Aurélio Porto, historiador do IHGRS, foi convidado para anotar o Processo Farroupilha, publicado pelo Arquivo Nacional em quatro volumes. ${ }^{10}$

A estratégia editorial, portanto, possuía raízes historiográficas recentes no contexto regional. Inserida na história dessas práticas eruditas, percebe-se, então, que
9. Nos primeiros debates do IHGRS, a autonomização do documento oficial levava, inclusive a condenações da interferência do historiador nos dados documentais. Assim, Lindolfo Collor prescrevia como método adequado ao estudioso da história a compilação e publicação dos documentos, "ou seja, o propósito do historiador deveria ser o de um copista e não de interpretação do material consultado. O mesmo deveria trabalhar só e sem outro objetivo que não o de salvar as informações que estavam guardadas nos arquivos" (SILVEIRA 2008, p. 26).

10. Em 1933, Aurélio Porto, então funcionário do Museu Júlio de Castilhos, foi cedido pelo interventor Flores da Cunha ao Governo Federal, vivendo, por cerca de um ano e meio, na capital da República para compor a edição do Processo. Segundo Martins: "Foi um trabalho ingente, cujo resultado impressiona pela dimensão da obra - mais de 2.000 páginas -, que destoa das publicações da época no Rio Grande do Sul, e mesmo das publicações dos dias atuais". 2016, p. 153). 
seu efeito poderia ser, também, o de dotar Terra Gaúcha de certo estatuto de documento. Não uma fonte fiel da realidade histórica retratada, dadas as muitas emendas necessárias, mas da evolução da pesquisa histórica no estado: "Ao escrever, portanto, esta sua 'Terra Gaúcha', estava o autor numa verdadeira nebulosa que iria desvendar, como desvendou, ainda que com dificuldades" (SPALDING 1955, p. 10).

Em outro sentido, o contexto de incipiente especialização das práticas letradas também oferecia apoio à extensa notação de Spalding. Na mesma época, uma matriz filológica fundamentava a recuperação de textos de antigos autores gaúchos, considerados precursores de movimentos literários, gêneros de escrita e disciplinas em desenvolvimento nas décadas de 1940 e 1950. Em 1952, por exemplo, o próprio Walter Spalding noticiava, em carta ao folclorista catarinense Oswaldo Cabral, um possível projeto de edição do Popularium Sul-Rio-Grandense, de Apolinário Porto Alegre, que receberia anotações de Augusto Meyer. ${ }^{11}$ No mesmo âmbito, a edição crítica dos Contos e Lendas também oferecia um precedente filológico recente no inventário da tradição cultural regional a que se dedicavam as diferentes facções intelectuais. As notas de Aurélio Buarque de Holanda à literatura de imaginação simoniana, elogiadas por nomes de prestígio nacional, apresentavam mais do que um vocabulário de regionalismos; eram um guia de leitura com atestado crítico de qualidade. Logo, a incorporação de Simões Lopes Neto na linhagem historiográfica dissidente do IHGRS podia aproveitar a bem-sucedida experiência de apropriação dos escritores modernistas, com a vantagem de ter amparo nas regras do próprio campo.

\section{No rodapé da história: debates historiográficos nas notas de Terra Gaúcha}

A edição Sulina de Terra Gaúcha apresenta um total de 165 notas de rodapé. Numa tentativa de classificação, as separei de acordo com os dois principais planos de intervenção: linguagem e conteúdo. No primeiro, temos algumas notas vocabulares e
11. Ver MARTINS 2016, p. 247. O empreendimento não foi concretizado pela Globo, porque seus editores não acreditavam em seu potencial comercial. 
correções de gramática e texto, como sistematizado no Quadro 1 , que segue abaixo.

\begin{tabular}{|l|l|l|l|}
\hline \multicolumn{1}{|c|}{$\begin{array}{c}\text { Seções/ } \\
\text { capítulos }\end{array}$} & Arcaísmos & Regionalismos & $\begin{array}{l}\text { Erros/texto } \\
\text { incompleto }\end{array}$ \\
\hline Critério & $\mathbf{1}(1)$ & $\mathbf{1}(2)$ & -- \\
\hline Nota preliminar & -- & $\mathbf{1}(12)$ & $\mathbf{1}(13)$ \\
\hline $\begin{array}{l}\text { I Tempos } \\
\text { D'Antanho }\end{array}$ & -- & -- & $\mathbf{3}(3,7,11)$, \\
\hline $\begin{array}{l}\text { II Primórdio } \\
\text { Português }\end{array}$ & -- & -- & $\mathbf{1}(17)$ \\
\hline $\begin{array}{l}\text { III Província dos } \\
\text { Tapes }\end{array}$ & -- & -- & -- \\
\hline $\begin{array}{l}\text { IV As Sete } \\
\text { Missões } \\
\text { Orientais }\end{array}$ & -- & $\mathbf{2}(13,15)$ & $\mathbf{2}(7,16)$ \\
\hline $\begin{array}{l}\text { V Ocupação } \\
\text { do Litoral Rio- } \\
\text { Grandense }\end{array}$ & -- & -- & $\mathbf{1}(6)$ \\
\hline TOTAL & $\mathbf{1}$ & $\mathbf{4}$ & $\mathbf{6}$ \\
\hline
\end{tabular}

Quadro 1: Notas sobre linguagem e texto em Terra Gaúcha

No plano das intervenções de conteúdo, há notas complementares, corretivas, explicativas e contestatórias, conforme o Quadro 2. Classifiquei como complementar toda nota que não se contrapõe a enunciados do texto principal. Nesse caso, temos enxertos biobibliográficos de Walter Spalding, detalhamento de informações e referências a documentos que comprovam afirmações de Simões Lopes Neto. As notas corretivas procuram dirimir equívocos factuais simples. As contestatórias diferem dessas últimas, por apresentarem contrapontos de interpretação, mesmo se apoiando em dados e fatos aparentemente objetivos. As explicativas atualizam conceitos simonianos e definem sentidos considerados obscuros no texto. Por fim, há notas que intervêm, ao mesmo tempo, na composição do texto e em seu conteúdo, buscando recompor a biobibliografia simoniana original. Nelas, são indicadas ao leitor as fontes bibliográficas do autor, citadas 
no texto ou inferidas pelo trabalho de pesquisa do anotador, e dados biográficos de personagens mencionados por Simões.

\begin{tabular}{|c|c|c|c|c|c|}
\hline $\begin{array}{c}\text { Seções/capí- } \\
\text { tulos }\end{array}$ & $\begin{array}{l}\text { Complementa- } \\
\text { res probatórios }\end{array}$ & $\begin{array}{c}\text { Corretivas- } \\
\text { factuais }\end{array}$ & Explicativos & Contestatórios & $\begin{array}{c}\text { Biobibliografia } \\
\text { simoniana }\end{array}$ \\
\hline Critério & -- & -- & -- & -- & -- \\
\hline $\begin{array}{l}\text { Nota } \\
\text { preliminar }\end{array}$ & $\begin{array}{c}1(2,3,5, \\
15,16,22,23, \\
25,26,29,32)\end{array}$ & $\begin{array}{l}\mathbf{5}(1,14,20, \\
31,33)\end{array}$ & $\begin{array}{l}5(6,9,10 \\
11,17)\end{array}$ & $\begin{array}{l}4(8,21,24, \\
27)\end{array}$ & $\begin{array}{l}\mathbf{5}(4,7,1819, \\
28)\end{array}$ \\
\hline $\begin{array}{l}\text { I Tempos } \\
\text { D'Antanho }\end{array}$ & $\begin{array}{l}8(1,6,8,9, \\
10,14,15,16)\end{array}$ & & $1(12)$ & $2(2,3)$ & $2(4,5)$, \\
\hline $\begin{array}{l}\text { II Primórdio } \\
\text { Português }\end{array}$ & $\begin{array}{l}15(1,4,5,6 \\
9,10,11,12 \\
15,16,20,21 \\
26,27,28)\end{array}$ & $\begin{array}{l}12(2,3,7 \\
13,14,18 \\
19,22,23 \\
25,29,30)\end{array}$ & $1(31)$ & $1(24)$ & $1(8)$ \\
\hline $\begin{array}{l}\text { III Província } \\
\text { dos Tapes }\end{array}$ & $\begin{array}{l}16(1,2,9, \\
11,13,14,16, \\
19,20,21,23, \\
24,25,27,28, \\
29)\end{array}$ & $\begin{array}{l}9(3,4,5,6, \\
7,17,18,22 \\
26)\end{array}$ & -- & $3(8,10,12)$ & $\mathbf{1}(15)$ \\
\hline $\begin{array}{l}\text { IV As Sete } \\
\text { Missões } \\
\text { Orientais }\end{array}$ & $\begin{array}{l}10(3,6,8, \\
10,11,17,18, \\
21,23,26)\end{array}$ & $\begin{array}{l}7(1,2,4,7 \\
9,13,25)\end{array}$ & 1 (19) & $\begin{array}{l}4(20,22,24, \\
27)\end{array}$ & $1(5)$ \\
\hline $\begin{array}{l}\text { V Ocupação } \\
\text { do Litoral } \\
\text { Rio- } \\
\text { Grandense }\end{array}$ & $\begin{array}{l}15(1,2,3,7, \\
10,11,16,18, \\
21,22,23,24, \\
25,27,28)\end{array}$ & $\begin{array}{l}9(5,8,9, \\
11 A, 15, \\
16 A, 19,20 \\
26)\end{array}$ & -- & $\begin{array}{l}4(12,13,14, \\
17)\end{array}$ & $1(4)$ \\
\hline TOTAL & 75 & 42 & 8 & 18 & 11 \\
\hline
\end{tabular}

Quadro 2 : Tipologia das notas de conteúdo em Terra Gaúcha

Chama a atenção, primeiramente, a grande desproporção quantitativa entre notas de correção ou esclarecimento de linguagem e texto (11) e comentários sobre o conteúdo do livro (154). O fato contradiz o argumento dos prefácios, pois demonstra o pequeno aproveitamento de linguagem regional em Terra Gaúcha, principal marca formal da ficção simoniana. A título de comparação, vale lembrar que a edição crítica de Holanda apresenta 489 notas para os Contos Gauchescos e 246 notas para as Lendas do Sul, majoritariamente vocabulares. Denota-se, daí, que o contraponto à avaliação de Meyer é 
nada mais do que um artifício retórico de persuasão, buscando aproveitar o recente capital simbólico adquirido por Simões Lopes Neto na produção cultural gaúcha, deslocando seu prestígio do campo literário para o debate historiográfico.

No plano das mediações de conteúdo, há preponderância de notas complementares, informativas e probatórias (75) sobre notas corretivas (42) e contestatórias (18). Também se verifica que a distribuição das notas se dá de forma razoavelmente equitativa entre os diversos capítulos do livro. A primeira interpretação possível é a de que o sistema de notação busca sanar uma lacuna formal, mais do que resolver os erros cometidos no texto anotado, o que garantiria ao ensaio simoniano o estatuto de historiografia. Segundo Grafton, as notas de rodapé históricas exercem duas funções. Primeiramente, elas "convencem o leitor de que o historiador realizou uma quantidade aceitável de trabalho" [...] (GRAFTON 1998, p. 30). No caso estudado, trata-se de um duplo convencimento, que reivindicava autoridade intelectual ao anotador e ao autor original. A segunda função do recurso é indicar "as principais fontes que o historiador realmente usou" (GRAFTON 1998, p. 30). Para cumprir essa exigência, foram acrescentadas 11 notas de reconstituição bibliográfica em Terra Gaúcha, algo talvez insuficiente para alcançar o padrão vigente na historiografia local dos anos 1920 a 1950, como vimos; o que também explica a grande quantidade de documentos e livros citados pelo anotador, incluindo muitas obras publicadas depois da produção do ensaio, mas que corroboram avaliações simonianas. As notas 5 e 26 do capítulo IV - "As Sete Missões Orientais" -, são bastante representativas dessa configuração. A primeira atribui os dados apresentados por Simões Lopes sobre a população de São Miguel às obras As missões Orientais e seus antigos domínios (1910), de Hemetério Veloso da Silveira, e História da República Jesuítica do Paraguai (1863), do Cônego João Pedro Gay. Na segunda, Walter Spalding transcreve por inteiro um documento dito inédito sobre o saque às missões orientais durante campanha argentina na segunda década do XIX, o que estende a nota de rodapé por 12 páginas de Terra 
Gaúcha (6 delas completamente tomadas pela transcrição).

A longa citação também possui um substrato ideológico. Ela fala do assalto de uma área de domínio brasileiro por forças castelhanas. Quando Simões Lopes Neto apresenta relatos semelhantes de ocupação luso-brasileira do território hispânico, a postura de Spalding é invariavelmente de objeção. Vale dizer, então, que tanto as notas de rodapé probatórias quanto as contestatórias tratam de temas problemáticos na memória histórica rio-grandense, passando pelo "diagnóstico cultural (português ou espanhol?) dos usos e costumes originais que definiriam o caráter rio-grandense" (NEDEL; RODRIGUES 2005 p. 172). Os quatro critérios científicos de prova ancorados em fontes bibliográficas e documentais (atualidade, quantidade, ineditismo e confiabilidade), então vigentes, podiam ser mobilizados seletivamente para refutar ou sustentar teses históricas de interesse do anotador, que construiu um complexo debate historiográfico nas notas de rodapé de Terra Gaúcha.

Como dito, Letícia Nedel e Mara Rodrigues identificaram Walter Spalding, assim como Manoelito de Ornellas, à corrente de memória histórica marginal dentro do IHGRS. Eram intelectuais polígrafos que, nos anos 1950, transitavam entre identidades profissionais de historiador e de folclorista. Atuavam em instituições alternativas de pesquisa, como o Museu Júlio de Castilhos e a Comissão Gaúcha de Folclore, mesmo sendo membros do Instituto, e costumavam mobilizar uma rede nacional de contatos para contornar as barreiras locais de acesso ao prestígio intelectual. No campo histórico, prescreviam uma aproximação com as Ciências Sociais e a ampliação dos objetos de estudo, os quais eram considerados atrelados em demasia, na produção dos adversários, à dinâmica política das elites. Segundo Nedel e Rodrigues, a sua conversão ao popular teria diferentes origens, como as conexões com as vanguardas literárias de São Paulo e Recife, ${ }^{12}$ a adesão à gauchesca platina ou uma possível dívida com o "culturalismo integrador de Gilberto Freyre". Com essa configuração, a "afirmação da heterogeneidade era a condição mesma da apreensão do território brasileiro" (NEDEL; RODRIGUES 2005, p. 172). 
Seria esperado, então, uma maior tolerância de Spalding a posições simonianas que poderiam, no novo contexto intelectual, ser associadas ao diagnóstico de pertencimento relativo do Rio Grande do Sul ao universo platino. Não é o que ocorre. 0 anotador parece detectar certo antilusitanismo simoniano, que busca desconstruir através da prova documental e do conceito positivo de verdade. Já na "Nota preliminar" de Terra Gaúcha, Spalding contesta a atribuição simoniana de fanatismo católico aos colonizadores portugueses. Na mesma seção, Simões Lopes Neto declara que o território rio-grandense pertencia à coroa espanhola em seu período de formação, o que justifica sua perspectiva narrativa colada à história administrativa da ocupação do Prata, com o estudo do sistema espanhol de exploração econômica, seu desenvolvimento institucional e a adoção de sua toponímia original. A contestação de Spalding vem em notas subsequentes, apelando sempre para a presença de luso-brasileiros no território, anteriormente à fundação de Rio Grande. Ao longo do último capítulo, "Ocupação do Litoral Rio-Grandense", o anotador intensifica a estratégia, recorrendo à documentação do povoado de Laguna "que, aliás, estava na sua quase totalidade absolutamente inédita". (SPALDING 1955, nota 23, p. 33), tomando, assim, o cuidado de atribuir a falta simoniana à debilidade dos arquivos, e não à sua possível imperícia. Mas em determinada passagem, o pelotense chega a dar notícia de tentativas frustradas de ampliação dos limites de Laguna em direção ao Sul, asseverando que: "Por aí ficou toda a interferência dos lagunenses no Rio Grande: duas nulas expedições improdutivas e a de João de Magalhães que redundou em apanha gados" (LOPES NETO 1955, 140). Spalding considera "injustiça" a afirmação de Simões e apoiase em documentos para dizer que a "cooperação lagunista no povoamento e formação do Rio Grande do Sul foi enorme" (SPALDING 1955, nota 12, p. 141).

No segundo capítulo, o anotador chega a justificar o direito de ocupação da região pelos portugueses através da interpretação de um ofício espanhol. Contrariamente ao alegado por Simões, a designação de Capitania d'El Rei seria prova 
da procedência lusitana da área, pois teria sido oficializada pelo soberano espanhol em alvará de Lisboa, durante a União Ibérica, ou seja, significaria "d'El Rei de Portugal" (SPALDING 1955 , nota 24 , p. 69). No terceiro capítulo, de título polêmico, "Província dos Tapes", ${ }^{13}$ Spalding comenta uma condenação simoniana ao preconceito racial, mas acaba por referendar um veto étnico vigente na historiografia dominante no IHGRS: à hispanidade na cultura local. Diz o anotador que os indígenas reduzidos tinham acesso à estrutura eclesiástica, podendo exercer o sacerdócio. Essa ausência ou minoração do preconceito racial facilitaria a constituição de uma identidade católica entre os guarani, não hispânica: "Essa uma das razões pelas quais, expulsos os jesuítas após tão longos anos de permanência nas Missões do Rio Grande do Sul (1626-1759), não ficaram vestígios maiores, espanhóis, nos usos, costumes e linguajar do gaúcho para cuja formação muito contribuíram os indígenas [...] (SPALDING 1955, nota 12, p. 81-82). Percebe-se, assim, que as ressalvas ao pertencimento político do Rio Grande do Sul à coroa espanhola tinham como mote profundo a negação da influência platina na vida cultural recente do estado. Desde a formalização da história política da região efetuada pelo IHGRS na década de 1920, o lusitanismo era uma ponte incontornável para a afirmação da brasilidade sul-rio-grandense; estratégia discursiva que Simões Lopes Neto não teve tempo de alcançar.

Ieda Gutfreind apontou que as diferenças entre as matrizes platinista e lusitanista da historiografia tradicional eram, na verdade, mais uma questão de grau do que de oposição cerrada. Segundo a autora, eram "frutos de uma só árvore". ${ }^{14}$ As duas tendências eram nacionalistas, mas a primeira teria maior tranquilidade em dialogar com a história dos países vizinhos e suas fontes. Nos anos 1950, haveria um esgotamento da corrente dominante, o que daria fôlego a teses controversas como as de Manoelito de Ornellas. Em Gaúchos e Beduínos, por exemplo, esse historiador afirmava que "A influência castelhana emprestou uma fisionomia inconfundível ao tipo humano das Missões e das zonas de Campanha" (ORNELLAS 1948b, p. 14-15). Fato explicado pelo domínio espanhol da
13. Denominação administrativa espanhola para o atual território do Rio Grande do Sul.

14. Na citação completa, Gutfreind fala da constituição do Iusitanismo nos anos 1920 e sua patrulha contra a corrente divergente: "Pode-se afirmar que eram frutos de uma só árvore, porém, contraditoriamente, o discurso 'valeriano' não seria mais aceito, porque estava em descompasso com o ritmo e o rumo da sociedade brasileira/ rio-grandense, enquanto que o outro ramo, representando o pensamento governamental sulino e também nacional, adaptara, desviando o curso do discurso, nele inserindo novas palavras de ordem, indicadores do novo projeto de integração nacional" (GUTFREIND 1992, p. 129). 
região até o início do século XIX. A hipótese testada aqui de que a edição póstuma de Terra Gaúcha foi uma tentativa de apropriação do escritor pelotense e de parcela da sua obra pelo grupo de historiadores folcloristas, identificado ao platinismo, também pode ser comprovada pelo intertexto. Apoiando-se no manuscrito ainda inédito, Ornellas recorreu à autoridade historiadora de Simões Lopes Neto para apoiar sua posição, transcrevendo uma observação que chamou de "comentário incisivo": "Com a criação da Província do Tapes em 1639, que foi a primeira divisão político-administrativa que teve o Rio Grande, prova-se que apenas por menos de um século esteve ele descurado do governo espanhol, ao passo que por dois séculos esteve-o do português [...]" (LOPES NETO apud ORNELLAS 1948b, p. 17-18). É interessante ver que Walter Spalding não corroborava as posições do colega prefaciador e mentor da edição póstuma de Terra Gaúcha. No último capítulo do ensaio simoniano, o anotador explicita os principais termos de seu desacordo com visão negativa dos lusitanos: "Simões Lopes Neto abeberou-se em fontes apaixonadas que sempre procuraram desfazer no português povoador, colonizador e explorador das terras brasílicas" (SPALDING 1955, nota 17, p. 149). Tais fontes seriam castelhanas.

Não era apenas na relação com o Prata que as anotações de Spalding destoavam doshistoriadores-folcloristas, aproximandose mais da historiografia dominante por eles combatida. Republicano e abolicionista, Simões Lopes Neto converteu seu cabedal de formação política em crítica ao preconceito racial. Isso implicava o reconhecimento da participação africana na formação cultural e étnica do Rio Grande do Sul. O peso da escravidão era, então, relativizado no cenário sulino. Quando Simões Lopes condena os maus tratos aos escravos indígenas e negros no Brasil, Spalding matiza sua ocorrência, assim como a própria instituição da escravidão, no estado: "Os maus tratos infligidos aos escravos negros era geral, na região açucareira e, depois, na cafeeira, mas havia exceções, e no Rio Grande do Sul, onde a escravidão foi quase nula, era raro ouvir-se dizer que um preto fora maltratado. Quanto a escravo índio, nunca 
houve, praticamente. [...] (SPALDING 1955 , nota 10, p. 77$).{ }^{15}$

O ponto de encontro do anotador com Simões Lopes Neto e a corrente platinista se restringia à questão indígena. Como vimos, Spalding considerava grande a contribuição étnica e cultural dos guarani, reduzidos nas missões jesuíticas, ao Rio Grande português. A declaração da filiação exigia um trabalho de higienização discursiva do imaginário indígena semelhante, no conteúdo, ao efetuado pelo romantismo oitocentista. Mas sua forma deveria ser historiográfica e científica, calcada em pesquisa e documentação. Assim, Spalding faz coro à minoração simoniana à existência de antropofagia, prática considerada bárbara, entre os nativos do Sul do Brasil: "Já no Rio Grande do Sul não há notícia de antropofagia, mesmo ritual, como em São Paulo onde, aliás, como no Nordeste e Norte, existiam viciados em carne humana, especialmente viciadas, verdadeiras megeras que não só preparavam as vítimas para os festins, como roubavam crianças para comerem!" (SPALDING 1955, nota 11 , p. 80). O tema era especialmente polêmico no momento de publicação de Terra Gaúcha, quando historiadores e outros intelectuais se debatiam publicamente sobre o "caso Sepé". Em 1955, a Comissão de História do IHGRS, liderada por Moysés Vellinho, deu parecer negativo à construção de um momumento em homenagem ao corregedor de São Miguel, Sepé Tiaraju, por ocasião do bicentenário de sua morte, ocorrida durante a guerra de resistência dos missioneiros à incorporação de seu território à América portuguesa pelo Tratado de Madri (1750). ${ }^{16}$

\section{Herculano e a instruçāo pública}

Como mostrado por Letícia Nedel, a oposição "platinismo/ lusitanismo" é apenas uma dentre outras antíteses acionadas nos esquemas de pensamento dos intelectuais locais, tais como "passadismo/modernismo", "regionalista/não regionalista". Se as duas últimas animaram o resgate crítico da ficção simoniana, a primeira, contudo, teve maior impacto na operação de reabilitação do ensaio histórico. O caso dos paratextos editoriais 
abordados também revela que intelectuais aparentemente ligados a polos rígidos de oposição, podiam, na verdade, se relacionar de maneira diversa com os esquemas mobilizados nessas disputas por espaço, de acordo com seus interesses práticos, como foi a tentativa de apropriação da imagem de Simões Lopes Neto. O lusitanismo de Spalding convivia bem com seu indigenismo. No sentido inverso, o reconhecimento da miscigenação e da tradição missioneira na cultura local não implicava em crítica ao mito da democracia racial, em sua forma sul-rio-grandense, que minorava a presença negra.

Se as posições ideológicas poderiam ser variáveis, a mediação da leitura de Terra Gaúcha cumpria, evidentemente, uma função de autolegitimação na luta pelos espaços de reconhecimento profissional. A história popular de Simões se prestava a sua apropriação por Ornellas e Spalding. Para isso, era necessário convencer que o escritor pelotense, então consagrado no cenário nacional como precursor do modernismo gaúcho, era também historiador. Esse reconhecimento público exigia certas concessões à vertente dominante do IHGRS. Daí a escolha de Spalding como anotador ser estratégica, já que seu nacionalismo insuspeito implicava menor rejeição do que o platinismo provocativo de Ornellas. ${ }^{17}$

Mas o tiro saiu pela culatra. Dificilmente alguém reconheceria, hoje em dia, Simões Lopes Neto como historiador. Sua imagem cristalizada no ideário intelectual é a de escritor regionalista, muito provavelmente à revelia de suas próprias autodefinições profissionais, como foi tratado na primeira parte deste artigo. É certo que o sucesso da ficção e o inventário crítico modernista têm grande responsabilidade nisso. Mas é muito significativo que os historiadores-folcloristas não tenham conseguido ultrapassar a barreira do grupo de literatos e historiadores da Globo às modalidades legítimas de relacionamento com o autor e sua obra. Nesse caso, o silêncio é tão revelador quanto o esquecimento. Não encontrei nenhuma resenha e sequer uma nota bibliográfica a respeito de Terra Gaúcha publicadas nos anos de 1955 e 1956 em periódicos
17. Mesmo nos livros mais dedicados ao folclore e à cultura popular, Walter Spal- ding enfatizava a ma- triz colonizadora aço- riana no Rio Grande do Sul, ponte para a afirmação da branqui- tude luso-brasileira do estado. Em Tradi- ções e superstições do Brasil Sul (1955), o grande espaço dedi- cado aos "açorianos, madeirenses e tras- montanos" se justifica assim: "São alicerces. Fundamento históri- CO" (SPALDING 1955, p. 9). 
especializados; nem na Revista do IHGRS e na Província de São Pedro, dominadas pelos historiadores estabelecidos e pelos modernistas/nacionalistas históricos, nem na Revista do Museu Júlio de Castilhos, principal veículo da oposição folclorista. ${ }^{18}$

Ainda que a edição póstuma de Terra Gaúcha tenha confessada missão de reabilitar a "faceta de historiador" de Simões Lopes Neto e, para isso, tenha se recorrido a técnicas científicas como a nota de rodapé histórica e a prova documental, a contestação às suas teses "platinistas" reforçou a avaliação negativa do ensaio. As mensagens paratextuais, portanto, tiveram efeito diverso do desejado. Spalding produziu, pela nota constestatória, uma autorização muito parcial. As notas probatórias e o aparato científico positivo anexado ao texto foram insuficientes para abalizar o autore, muito provavelmente, reforçaram o veto à identidade profissional de historiador para Simões Lopes Neto.

\section{REFERÊNCIAS BIBLIOGRÁFICAS}

CORADINI, Odaci Luiz. As missões da "cultura" e da "política": confrontos e reconversões de elites culturais e políticas no Rio Grande do Sul (1920-1960). Estudos históricos, Rio de Janeiro, n. 32, 2003, p. 125-144.

GENETTE, Gérard. Paratextos editoriais. São Paulo: Ateliê Editorial, 2009.

GRAFTON, Anthony. As origens trágicas da erudição: pequeno tratado sobre a nota de rodapé. Campinas: Papirus, 1998.

GUTFREIND, Ieda. A historiografia rio-grandense. Porto Alegre: Editora da UFRGS, 1992.

LOPES NETO, João Simões. Terra Gaúcha. Porto Alegre: Sulina, 1955.
18. O único eco encontrado do lançamento da obra está na imprensa ordinária: uma rápida nota, em 1955, na seção "Livros", do jornal Correio do Povo, o mesmo que abrigou a coluna "Prosa das terças", de Manoelito de Ornellas. 
MEYER, Augusto. Correspondência, 14 abr. 1954, Rio de Janeiro, para SIMÕES LOPES, Francisca Meirelles. Álbum Simoniano, Biblioteca Pelotense, p. 128.

MARTINS, Jefferson Telles. O Instituto Histórico e Geográfico do Rio Grande do Sul e o espaço social dos intelectuais: trajetória institucional e estudo das redes de solidariedade (e conflitos) entre intelectuais (1920-1956). Tese (Doutorado em História). Programa de Pós-Graduação em História, Pontifícia Universidade Católica do Rio Grande do Sul, Porto Alegre, 2016.

MICELI, Sergio. Intelectuais e Classe dirigente no Brasil (1920-1945). São Paulo: Difel, 1979.

NEDEL, Letícia Borges. Paisagens da Província: o regionalismo sul-rio-grandense e o Museu Júlio de Castilhos nos anos cinquenta. Dissertação (Mestrado em História Social). Programa de Pós-Graduação em História Social, Universidade Federal do Rio de Janeiro, Rio de Janeiro, 1999.

\section{. Um passado novo para uma História em}

crise: regionalismo e folcloristas no Rio Grande do Sul. Tese (Doutorado em História). Instituto de Ciências Humanas, Programa de Pós-Graduação em História, Universidade de Brasília, Brasília, 2005.

NEDEL, Letícia Borges, RODRIGUES, Mara de Mattos. Historiografia, crítica e autocrítica. Ágora, Santa Cruz do Sul, v. 11, n. 1, jan./jun. 2005, p. 161-186.

ORNELLAS, Manoelito de. Gaúchos e beduínos: a origem étnica e a formação do Rio Grande do Sul: Rio de Janeiro: José Olympio, 1948.

. Prefácio. In: LOPES NETO, João Simões. Terra Gaúcha. Porto Alegre: Sulina, 1955, p. 7-8. . Um pouco de Simões Lopes Neto. Correio do Povo, Porto Alegre, 16 mar. 1948, p. 4. 
SILVEIRA, Daniela Oliveira. "O passado está prenhe do futuro": a escrita da história no Instituto Histórico e Geográfico do Rio Grande do Sul (1920-1930). Dissertação (Mestrado em História). Programa de Pós-Graduação em História, Universidade Federal do Rio Grande do Sul, Porto Alegre, 2008.

SIMÕES LOPES, Francisca Meirelles. Correspondência, 04 jan. 1954, Pelotas, para ORNELLAS, Manoelito de. Porto Alegre. Álbum Simoniano, Biblioteca Pelotense.

ORNELLAS, Manoelito de. Correspondência, 01 jan. 1954, Pelotas, para Editores da Editora Globo S. A., Porto Alegre. Álbum Simoniano, Biblioteca Pelotense.

SPALDING, Walter. Introdução. In: LOPES NETO, João Simões. Terra Gaúcha. Porto Alegre: Sulina, 1955, p. 9-12. . Tradições e superstições do Brasil Sul. Rio de Janeiro: Organizações Simões, 1955.

ZALLA, Jocelito. Quanto a Literatura fala à História: a ficção de Barbosa Lessa e a memória pública no Rio Grande do Sul. História da Historiografia, v. 16, 2014, p. 37-54.

\section{AGRADECIMENTOS E INFORMAÇŌES}

\section{Jocelito Zalla}

jocelito.zalla@ufrgs.br

Professor do Colégio de Aplicação

Universidade Federal do Rio Grande do Sul

Av. Bento Gonçalves, 9500 - Prédio 43815 - Agronomia

91501-970 - Porto Alegre - RS

Brasil 